OPEN ACCESS

Edited by:

Tatiana Venkova,

University of Texas Medical

Branch-Galveston, USA

Reviewed by:

Dhruba Chattoraj,

National Institutes of Health, USA

Martin Marinus,

University of Massachusetts, USA

*Correspondence:

Anders Løbner-Olesen

lobner@bio.ku.dk

${ }^{\dagger}$ These authors have contributed equally to this work.

Specialty section:

This article was submitted to

Molecular Recognition,

a section of the journal

Frontiers in Molecular Biosciences

Received: 24 May 2016 Accepted: 14 June 2016

Published: 28 June 2016

Citation:

Riber L, Frimodt-Møller J, Charbon G and Løbner-Olesen A (2016) Multiple DNA Binding Proteins Contribute to Timing of Chromosome Replication in

E. coli. Front. Mol. Biosci. 3:29.

doi: 10.3389/fmolb.2016.00029

\section{Multiple DNA Binding Proteins Contribute to Timing of Chromosome Replication in E. coli}

\author{
Leise Riber ${ }^{\dagger}$, Jakob Frimodt-Møller ${ }^{\dagger}$, Godefroid Charbon and Anders Løbner-Olesen * \\ Section for Functional Genomics and Center for Bacterial Stress Response and Persistence, Department of Biology, \\ University of Copenhagen, Copenhagen, Denmark
}

Chromosome replication in Escherichia coli is initiated from a single origin, oriC. Initiation involves a number of DNA binding proteins, but only DnaA is essential and specific for the initiation process. DnaA is an AAA + protein that binds both ATP and ADP with similar high affinities. DnaA associated with either ATP or ADP binds to a set of strong DnaA binding sites in oriC, whereas only DnaA ${ }^{\text {ATP }}$ is capable of binding additional and weaker sites to promote initiation. Additional DNA binding proteins act to ensure that initiation occurs timely by affecting either the cellular mass at which DNA replication is initiated, or the time window in which all origins present in a single cell are initiated, i.e. initiation synchrony, or both. Overall, these DNA binding proteins modulate the initiation frequency from oriC by: (i) binding directly to oriC to affect DnaA binding, (ii) altering the DNA topology in or around oriC, (iii) altering the nucleotide bound status of DnaA by interacting with non-coding chromosomal sequences, distant from oriC, that are important for DnaA activity. Thus, although DnaA is the key protein for initiation of replication, other DNA-binding proteins act not only on oriC for modulation of its activity but also at additional regulatory sites to control the nucleotide bound status of DnaA. Here we review the contribution of key DNA binding proteins to the tight regulation of chromosome replication in E. coli cells.

Keywords: $E$. coli, chromosome replication, DNA binding proteins, cell mass, initiation synchrony

\section{TIMING OF INITIATION OF CHROMOSOME REPLICATION IN E. COLI}

Chromosome replication in Escherichia coli is initiated from a single replication origin, oriC. The oriC-encoded structural and functional instructions for initiation are well-described (Leonard and Mechali, 2013; Skarstad and Katayama, 2013). In brief, the minimal oriC contains two functional regions: the Duplex Unwinding Element (DUE), which comprises three AT-rich repeat sequences of each $13 \mathrm{bp}$, and the flanking DnaA Assembly Region (DAR) (Figure 1; Mott and Berger, 2007; Ozaki and Katayama, 2012). DnaA is the initiator protein responsible for DUE opening and for the recruitment of replisome components and is the only protein that is both essential and specific for the initiation process (Kaguni, 2011; Leonard and Grimwade, 2011). DnaA belongs to the AAA+ proteins (ATPases Associated with diverse Activities) and can bind both ATP and ADP with similar high affinities (Sekimizu et al., 1987). The DAR region contains high affinity DnaA Boxes (R1, R4, and R2) that bind both DnaA ${ }^{\text {ATP }}$ and DnaA ${ }^{A D P}$, along with multiple low affinity sites (R3, R5/M, I1, I2, I3, C1, C2, C3, 1 , and $\tau 2)$ that bind DnaA ${ }^{\text {ATP }}$ 
(McGarry et al., 2004; Kawakami et al., 2005; Rozgaja et al., 2011). The DAR region also contains recognition sequences for two additional DNA binding proteins; IHF and Fis (Figure 1; Polaczek, 1990; Gille et al., 1991).

Throughout most of the cell cycle oriC is bound by DnaA located at R1, R2, and R4. This origin recognition complex (ORC) serves dual purposes in setting the stage for proper orisome assembly and preventing premature DNA unwinding. The ratio of DnaA ${ }^{\text {ATP }}$ to DnaA ${ }^{A D P}$ varies through the cell cycle and the peak at about $70-80 \% D_{\text {DnaA }}{ }^{\text {ATP }}$ coincides with replication initiation (Kurokawa et al., 1999). In the current model for orisome formation, two converging DnaA ${ }^{\text {ATP }}$ filaments are formed (Rozgaja et al., 2011). One filament originates from R4 and grows leftward. This R4-filament displaces Fis from its binding site next to R2, which allows IHF to bind its recognition sequence next to $\mathrm{R} 1$. IHF bends the DNA $180^{\circ}$ thereby bringing $\mathrm{R} 1$ in proximity of $\mathrm{R} 5$ and allows for the formation of the rightward filament responsible for duplex opening at the DUE, DnaC assisted helicase loading and assembly of the replisome (Leonard and Grimwade, 2011, 2015; Ozaki et al., 2012). Following initiation, DnaA ${ }^{\text {ATP }}$ is converted to $D_{n a A}{ }^{A D P}$ primarily by a process called regulatory inactivation of DnaA (RIDA), which is dependent on the Hda protein bound to ADP and the DNA-loaded $\beta$-clamp of the polymerase III holoenzyme (Kato and Katayama, 2001), and by the less efficient datA-dependent DnaA ${ }^{\text {ATP }}$ hydrolysis (DDAH). DDAH takes place at $\operatorname{dat} A$ and is dependent on IHF (Figure 1; Kasho and Katayama, 2013).

\section{Coordination of Initiations with Cell Mass Increase}

A long standing observation is that initiation of chromosome replication occurs when a certain cellular mass per origin, the initiation mass, is reached (Donachie, 1968; Hill et al., 2012). This coupling of replication initiation to cell growth depends on the DnaA protein. Earlier studies indicate that accumulation of DnaA protein sets the time of initiation in the cell cycle especially around or below wild-type level (Løbner-Olesen et al., 1989). On the other hand, a coordinated increase in DnaA ${ }^{\text {ATP }}$ and DnaA $^{A D P}$ does not significantly increase initiation (Kurokawa et al., 1999; Flatten et al., 2015), suggesting that accumulation of DnaA ${ }^{\text {ATP }}$ is insufficient to trigger initiation. However, in the absence of RIDA, where DnaA is mainly ATP bound, a modest increase in DnaA ${ }^{\text {ATP }}$ level leads to excessive initiations from oriC (Riber et al., 2006; Fujimitsu et al., 2008), as does expression of a DnaA mutant protein insensitive to RIDA (Simmons et al., 2004). Together, this indeed suggests that accumulation of DnaA $^{\text {ATP }}$ triggers initiation, whereas this effect can be offset by a similar increase in DnaA ${ }^{A D P}$ (Donachie and Blakely, 2003). The participation of $\mathrm{DnaA}^{\mathrm{ADP}}$ in orisome formation remains unclear (Leonard and Grimwade, 2015), but the above observations suggest that it affects initiation negatively. Overall, accumulation of DnaA protein during steady-state growth, along with the cell cycle specific peak in $\mathrm{DnaA}^{\mathrm{ATP}} / \mathrm{DnaA}^{\mathrm{ADP}}$ ratio, determines the onset of initiation with little variation between individual cells.

\section{Coordination of initiations within a Single Cell}

In individual cells, initiation at all origins occurs within approximately $1 / 10$ of the doubling time (Initiation period, $\mathrm{I}^{\mathrm{P}}$; Figure 2A). Rapidly growing cells with overlapping replication cycles therefore predominantly contain $2^{\text {n }}(n=1,2,3)$ copies of oriC, referred to as initiation synchrony (Skarstad et al., 1986). Initiation synchrony depends on the immediate inactivation of newly replicated origins by sequestration. oriC contain 11 copies of the sequence GATC that are methylated by Dam methyltransferase and bound, i.e., sequestered, by SeqA when hemimethylated. Sequestration prevents DnaA binding to its weak sites in oriC (Nievera et al., 2006) for approximately $1 / 3$ generation (Sequestration period, $\mathrm{S}^{\mathrm{P}}$; Figure 2A) and serves to keep track of which origins have been initiated (Boye and Løbner-Olesen, 1990; Campbell and Kleckner, 1990; Lu et al., 1994). The ability to initiate all origins in synchrony could result from maintaining a high DnaA $^{\text {ATP }}$ level throughout $\mathrm{I}^{\mathrm{P}}$. Alternatively the first origin initiated may release its $\mathrm{DnaA}^{\mathrm{ATP}}$ to assist in triggering successive initiations at remaining origins in a cascade-like manner to ensure that free DnaA ${ }^{\text {ATP }}$ increases through $\mathrm{I}^{\mathrm{P}}$ and enforces synchrony (Løbner-Olesen et al., 1994). These models predict different outcomes for sequestration deficient cells. A high DnaA ${ }^{\text {ATP }}$ level throughout $\mathrm{I}^{\mathrm{P}}$ would result in re-initiation(s) within $\mathrm{I}^{\mathrm{P}}$, asynchrony and overinitiation. The cascade model predicts a delay between successive initiations due to newly initiated origins competing with old origins for a limited amount of DnaA ${ }^{\text {ATP }}$. The initiation frequency would be directly proportional with accumulation of DnaA ${ }^{\text {ATP }}$ resulting in asynchrony but an unchanged overall initiation frequency, which is in accordance with experimental observations for Dam deficient cells (Boye and Løbner-Olesen, 1990; Løbner-Olesen et al., 1994).

Synchrony is only observed when $\mathrm{I}^{\mathrm{P}}<\mathrm{S}^{\mathrm{P}}$ (Figure 2A). In cells with aberrant timing of initiation, the $\mathrm{I}^{\mathrm{P}}$ and $\mathrm{S}^{\mathrm{P}}$ periods change, i.e., either start earlier in the cell cycle at a decreased initiation mass, i.e., overinitiation, or are delayed with an increased initiation mass, i.e., underinitiation. Alternatively, the duration of $\mathrm{I}^{\mathrm{P}}$ and $\mathrm{S}^{\mathrm{P}}$ may change relative to each other, and when $\mathrm{I}^{\mathrm{P}}>\mathrm{S}^{\mathrm{P}}$, newly initiated origins, released from sequestration, compete with origins not yet initiated. Consequently, some origins are re-initiated while others are not initiated at all, leading to loss of synchrony (Olsson et al., 2003; Skarstad and LøbnerOlesen, 2003). This is exemplified by dam mutants without a sequestration period that initiate throughout the cell cycle (Figure 2B; Boye and Løbner-Olesen, 1990; Lu et al., 1994). seqA mutants are also asynchronous but have a higher origin concentration, possibly because DnaA is increased, relative to dam mutants (Figure 2C; Campbell and Kleckner, 1990; von Freiesleben et al., 1994). Increased levels of Dam will, due to faster re-methylation rates, reduce $S^{\mathrm{P}}$ and when this becomes shorter than $\mathrm{I}^{\mathrm{P}}$, asynchrony follows (Figure 2C; Boye and LøbnerOlesen, 1990; von Freiesleben et al., 2000a). Excess SeqA protein delays initiation, prolongs the sequestration period but does not affect synchrony (Figure 2D; Bach et al., 2003; Charbon 


\section{oric}

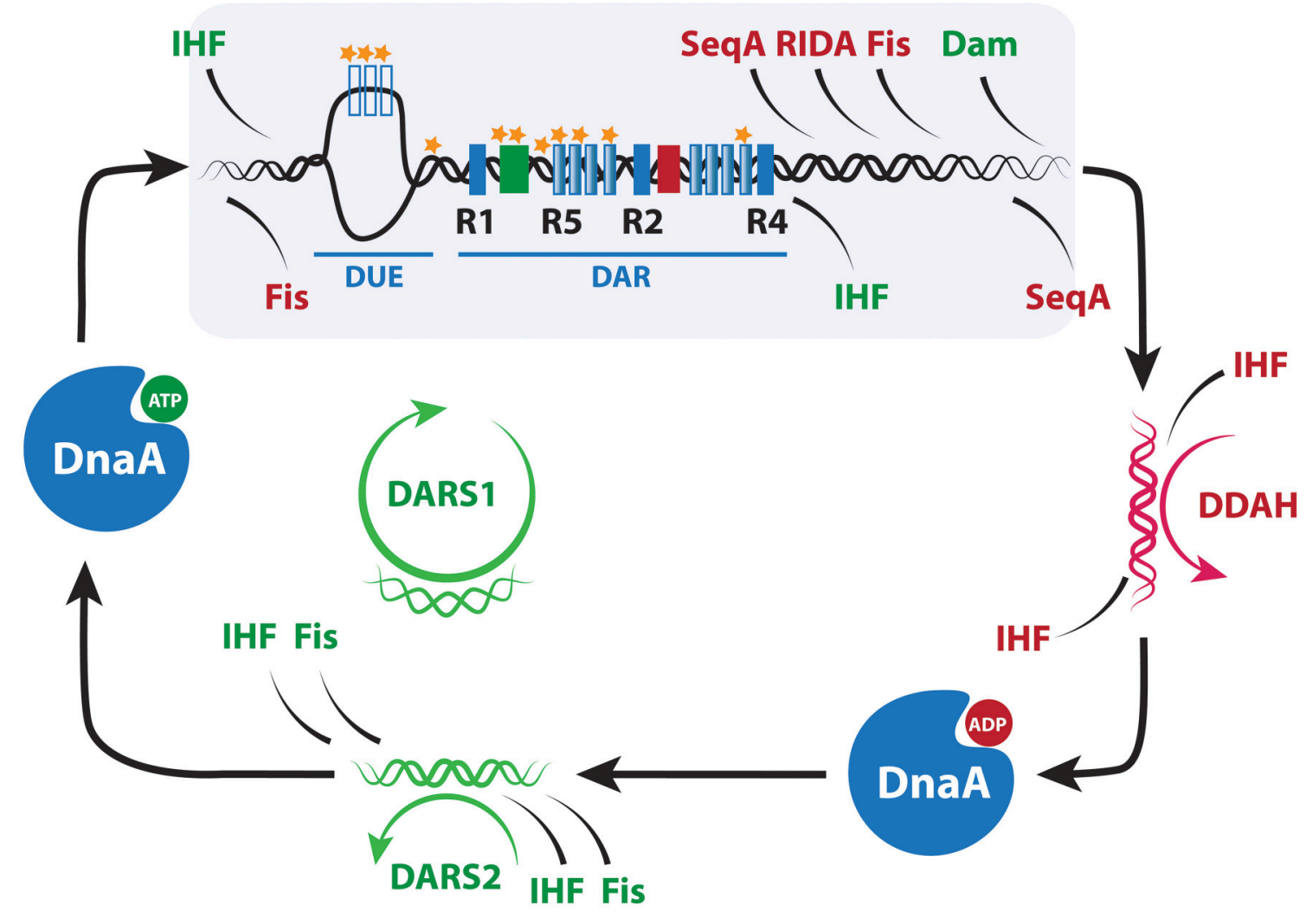

:DnaA Binding site-high affinity
$\square:$ :DnaA Binding site-low affinity
:DnaA Binding site-single stranded
:IHF Binding site
: Fis Binding site
: GATC

FIGURE 1 | The chromosome replication cycle. Dynamic binding of activators (green) and inhibitors (red) to oriC and distal regulatory sequences during the replication cycle. For details see text.

et al., 2011). During sequestration the activity of DnaA is lowered by RIDA and DDAH. RIDA is presumably accelerated by generation of new replication forks at initiation and hence more DNA loaded $\beta$-clamps (Moolman et al., 2014). Similarly, DDAH is increased shortly after initiation when the datA locus is duplicated and together they ensure a post-initiation decrease in the DnaA ${ }^{\mathrm{ATP}} / \mathrm{DnaA}^{\mathrm{ADP}}$ ratio (Figure 1). RIDA $(\Delta h d a)$ and to a lesser degree DDAH $(\Delta$ datA) deficient cells fail to lower the ratio of DnaA ${ }^{\mathrm{ATP}} / \mathrm{DnaA}^{\mathrm{ADP}}$ to prevent re-initiation following sequestration. This results in asynchrony and early initiation at a reduced cell mass (Figure 2E; Kitagawa et al., 1998; Fujimitsu et al., 2008; Kasho and Katayama, 2013). On the other hand, the $\operatorname{nnaN}_{G 157 C}$ mutant, which is more active in RIDA (dnaN encodes the $\beta$-clamp), or extra copies of $\operatorname{dat} A$, results in delayed initiation and, for $d_{n a N_{G 157 C}}$ cells, also produces asynchrony (Figures 2F,G; Morigen et al., 2001; Gon et al., 2006; Charbon et al., 2011; Johnsen et al., 2011). During sequestration, the overall level of free DnaA is reduced by titration (Hansen et al., 1991; 


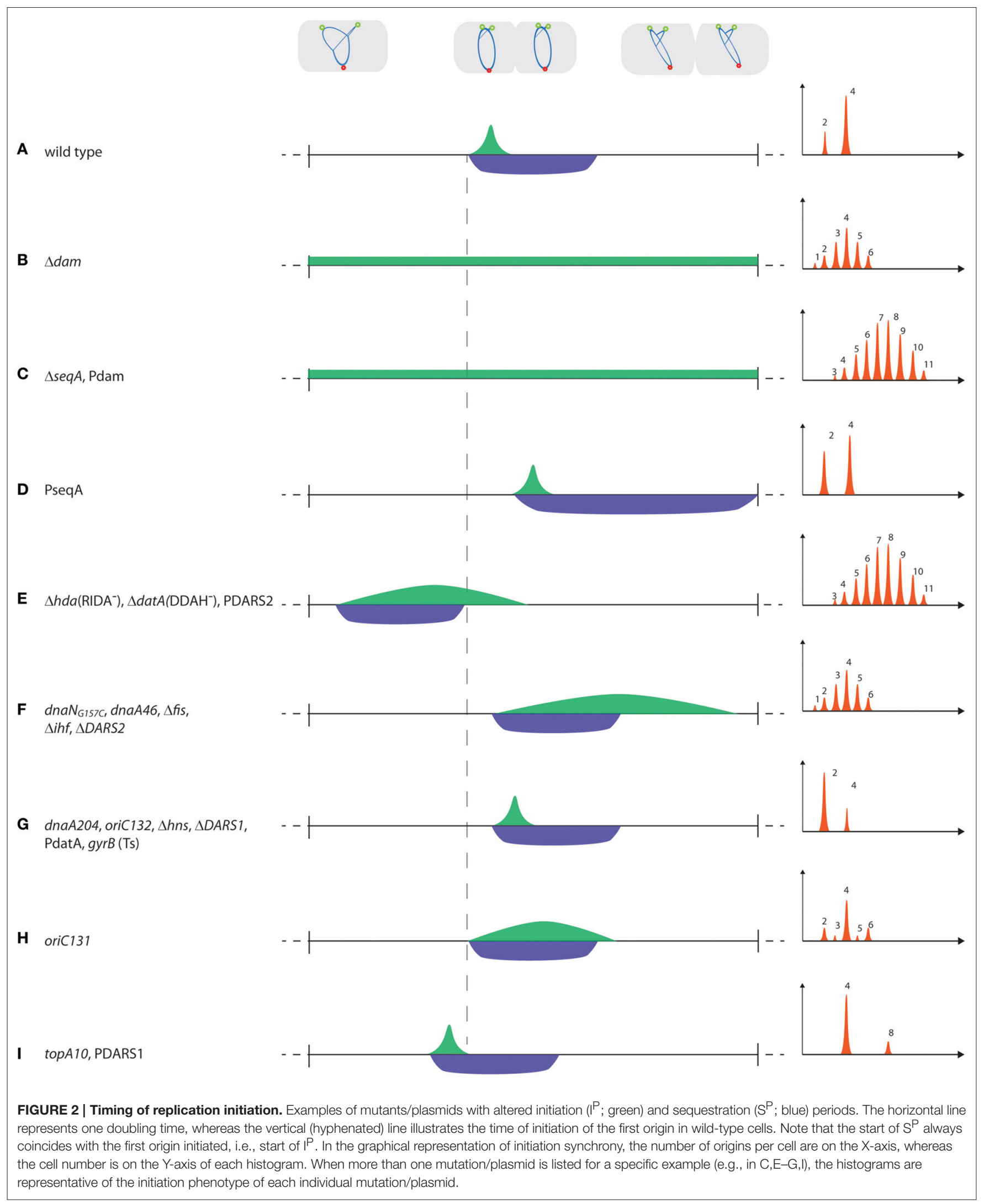


Kitagawa et al., 1996, 1998; Ogawa et al., 2002) and by arrest of de novo DnaA synthesis (Campbell and Kleckner, 1990).

\section{MODULATION OF TIMING OF REPLICATION INITIATION BY DNA BINDING PROTEINS}

Several DNA binding proteins affect either the cell mass at initiation, the initiation synchrony, or both. These proteins either bind specifically to oriC to affect DnaA binding, non-specifically to DNA to alter oriC topology, or they bind sequences important for the nucleotide bound status of DnaA.

\section{Proteins That Specifically Interact with oriC Prior to Initiation}

The most important protein to interact with oriC prior to initiation is DnaA. Mutations in DnaA that affect nucleotide binding, such as dnaA46, are presumably somewhat deficient in formation of DnaA multimers on oriC, which results in delayed initiation and a prolonged initiation period (Skarstad et al., 1988; Boye et al., 1996). As sequestration remains unchanged $\left(\mathrm{I}^{\mathrm{P}}>\mathrm{S}^{\mathrm{P}}\right)$, dnaA46 cells are asynchronous (Figure 2F; Skarstad and LøbnerOlesen, 2003). Mutations in DnaA that affect DNA binding, but not nucleotide binding (e.g., dnaA204), lead to late but synchronous initiation (Figure 2G; Skarstad et al., 1988; Torheim et al., 2000). The ability to form DnaA ${ }^{\text {ATP }}$ filaments on oriC therefore seems of greater importance for initiation synchrony than a tight anchoring to DnaA binding sites.

Conflicting data exist on the role of Fis for timing of initiation. Binding Fis to oriC in vitro is reported to either inhibit initiation of replication by inducing conformational changes at oriC that prevent orisome formation (Wold et al., 1996; Ryan et al., 2002, 2004), or have no effect on initiation (Margulies and Kaguni, 1998). Cells with a mutated primary Fis binding in oriC (oriC131) have an origin concentration similar to wild-type (Figure 2H; Weigel et al., 2001; Riber et al., 2009; Flatten and Skarstad, 2013). Fis-deficient cells, on the other hand, have a lowered origin concentration (Flatten and Skarstad, 2013; Kasho et al., 2014), suggesting that initiation is delayed (Figure 2F). However, because Fis affects multiple cellular processes due to its involvement in DNA organization one should be careful in assessing its role in initiation solely based on the behavior of Fis-deficient cells. Both Fis deficiency or loss of its primary oriC binding site result in initiation asynchrony (Figures $2 \mathrm{~F}, \mathbf{H}$; Riber et al., 2009; Flatten and Skarstad, 2013), indicating that these cells are deficient for proper orisome assembly and/or for preventing premature DNA unwinding. The role of IHF in replication timing is less controversial. An oriC mutant with a disrupted IHF binding site (oriC132) is somewhat deficient in orisome formation and has delayed but synchronous initiation (Figure 2G; Weigel et al., 2001; Skarstad and Løbner-Olesen, 2003; Riber et al., 2009). ihf mutant cells also initiate replication at an increased mass per origin consistent with a stimulatory role of IHF on initiation. Cells deficient in IHF are on the other hand asynchronous (Figure 2F; von Freiesleben et al., 2000b).
This is in agreement with an additional role of IHF for DnaA ${ }^{\text {ATP }}$ generation at DARS2 (see below).

A number of proteins negatively regulate initiation of replication in vitro. These include ArcA that binds to 13 mer AT rich repeats, to DnaA box R1 and to the IHF binding site in oriC, and IciA that binds to 13-mer AT-rich repeats in oriC (Hwang and Kornberg, 1990; Lee et al., 2001). The impact of ArcA and IciA on replication initiation in vivo is modest (Nystrom et al., 1996) or not known, respectively. The stationaryphase induced CspD protein binds ssDNA to inhibit replication initiation and elongation in vitro, whereas no in vivo data are available (Yamanaka et al., 2001). Upon association with Cnu and/or Hha, H-NS (see below) binds to a specific sequence in oriC that overlaps DnaA box R5 (Kim et al., 2005; Yun et al., 2012). Cells deficient in $\mathrm{Cnu}$ and/or Hha are, however, similar to wildtype (Kim et al., 2005). Finally, the protein Rob binds to a single site in oriC in vitro, but does not affect initiation in vivo (Skarstad et al., 1993).

\section{DNA Binding Proteins That Affect Topology of oriC}

In E. coli the genomic DNA is mostly negatively supercoiled (Wang et al., 2013). Unconstrained supercoiling of oriC contributes to the ease of duplex opening and is determined by transcription (not covered here; for review see Magnan and Bates, 2015) along with the actions of topoisomerase I and DNA gyrase enzymes (Wu et al., 1988). Mutations in topoisomerase I, which removes negative supercoils, result in initiation at a slightly reduced mass while synchrony is maintained (Figure 2I; von Freiesleben and Rasmussen, 1992; Olsson et al., 2003). Conversely, temperature sensitive gyrB mutant cells, with moderately reduced negative superhelicity of the chromosome, enhance the temperature sensitivity of a dnaA46 mutant (Filutowicz, 1980) and show delayed synchronous initiations (Figure 2G; von Freiesleben and Rasmussen, 1991; Usongo et al., 2013). This suggests that initiation is facilitated by an increase in negative superhelicity of the chromosome. However, topA-gyr mutations influence chromosome segregation, R-loop formation and possibly induce stable DNA replication independent of oriC (Usongo et al., 2013, 2016) making it difficult to assess the effect of large changes in overall supercoiling on replication initiation. In vivo, nucleoid-associated proteins (NAPs; Dillon and Dorman, 2010), such as IHF, Fis, H-NS, HU, and MukFEB constrain negative supercoils to condense the chromosome and could therefore affect initiation of chromosome replication (Badrinarayanan et al., 2015; Lal et al., 2016). H-NS deficient cells have an increased negative superhelicity of the genome (Mojica and Higgins, 1997; Hardy and Cozzarelli, 2005). Yet, genetic evidence suggests that loss of H-NS hampers initiation (Katayama et al., 1996), and H-NS deficient cells initiate replication in synchrony at an increased cell mass (Figure 2G; Kaidow et al., 1995; Atlung and Hansen, 2002). The HU protein can substitute for IHF in DnaA-mediated unwinding of oriC in vitro (Hwang and Kornberg, 1992) although their mechanisms of action differ (Ryan et al., 2002). In vivo, genetic evidence suggests that loss of HU stimulates initiation despite decreased negative 
supercoiling (Louarn et al., 1984). Loss of MukB, involved in condensation of the bacterial chromosome (Hiraga et al., 1989; Cui et al., 2008), results in reduced negative supercoiling (Weitao et al., 2000), but initiations remain synchronous (Weitao et al., 1999). It is not known whether MukB affects the initiation mass. Finally, the starvation-induced NAP, Dps, binds non-specifically to oriC, and interacts with the N-terminus of DnaA, inhibiting DNA unwinding in vitro. Loss of Dps does not result in loss of synchrony, but increases the cellular origin content somewhat (Chodavarapu et al., 2008). In summary, it seems that NAPs modulate replication initiation but that the effect is not solely mediated through an effect on DNA supercoiling.

\section{GETTING READY FOR THE NEXT ROUND OF REPLICATION}

At later cell cycle stages DnaA ${ }^{\text {ATP }}$ is regenerated for the next initiation to take place (Figure 1). E. coli can rejuvenate $D_{n a A}{ }^{A D P}$ to $D_{n a A}{ }^{A T P}$ in a process assisted by acidic phospholipids (Saxena et al., 2013) or at two non-coding chromosomal sites called DARS1 and DARS2 (Fujimitsu et al., 2009). DARS1 and DARS2 are located in each replichore halfway between oriC and ter $C$, and are duplicated after the end of sequestration. Multiple DnaA ${ }^{\mathrm{ADP}}$ molecules form complexes with DARS to facilitate release of ADP resulting in apo-DnaA, which will primarily rebind ATP as this is more abundant than ADP within the cell (Petersen and Møller, 2000).

$D A R S 1$ is not known to be regulated by any proteins, whereas rejuvenation at the more efficient DARS2 locus is dependent on binding of both IHF and Fis (Kasho et al., 2014). While Fis binds DARS2 throughout the cell cycle, IHF provides cell cycle specificity to DARS2 activity by only binding and activating $D A R S 2$ immediately prior to initiation to ensure an increase in DnaA $^{\text {ATP }}$ level (Fujimitsu et al., 2009; Kasho et al., 2014). Extra copies of DARS1 or DARS2 will increase the overall DnaA ATP level, which results in early initiation (Figures 2E,I) and for DARS2 also extends $\mathrm{I}^{\mathrm{P}}$, thereby resembling RIDA deficiency (Figure 2E; Fujimitsu et al., 2009; Charbon et al., 2011). Deletion of DARS1, DARS2, or both reduces the ability to reactivate DnaA for new initiations in the following cell cycle and results in delayed initiation (Figures 2F,G; Fujimitsu et al., 2009; Kasho et al., 2014; Frimodt-Moller et al., 2015). Loss of DARS2 also increases the relative duration of the initiation period, leading to initiation asynchrony (Figure 2F; Fujimitsu et al., 2009; Frimodt-Moller et al., 2015). This suggests that both DARS1 and DARS2 are important for coupling initiation to cell mass increase, whereas only the cell-cycle regulated DARS2 is crucial for maintaining initiation synchrony.

\section{REFERENCES}

Atlung, T., and Hansen, F. G. (2002). Effect of different concentrations of H-NS protein on chromosome replication and the cell cycle in Escherichia coli. J. Bacteriol. 184, 1843-1850. doi: 10.1128/JB.184.7.1843-18 50.2002

\section{CONCLUDING REMARKS}

Overall, timing of chromosome replication in E. coli takes place at least at two levels. First, initiation of replication is tightly coupled to cell mass increase through accumulation of DnaA $^{\text {ATP }}$. Second, synchrony of initiations within the single cell is not necessarily connected to initiation mass but results from each origin being simultaneously initiated only once per generation, with asynchrony originating from failure to obey this once-and-only-once rule. DnaA remains the only replication protein solely required for initiation at oriC, but additional proteins act on oriC and elsewhere to assist in coupling of replication to cell growth and synchrony. In particular IHF and Fis display complex functions, targeting several regulatory sites. IHF has a dual role on replication initiation, acting both positively (i.e., binding to DARS2 and oriC) and negatively (i.e., binding to $\operatorname{dat} A$ ). Also, IHF binds oriC at the pre-initiation stage and interacts with $\operatorname{dat} A$ and DARS2 following initiation. Binding of IHF to these regions is suggested to be temporally regulated so that IHF binds to oriC, to datA and to DARS2 in a successive manner during cell cycle progression (Kasho and Katayama, 2013; Kasho et al., 2014). In vivo, ihf mutants display an initiation-compromised phenotype, indicating that the overall role of IHF on initiation of replication appears positive.

For a long time, the contribution of Fis in initiation regulation has been questioned. Recent studies do, however, suggest an overall positive role of Fis in replication initiation (Flatten and Skarstad, 2013; Kasho et al., 2014), which likely results from ensuring ordered orisome formation by preventing premature IHF binding and DNA unwinding (Leonard and Grimwade, 2015) and from stimulating DnaA ${ }^{\text {ATP }}$ rejuvenation at DARS2. As the cellular Fis level depends on both growthrate and phase, it could adjust chromosome replication to the bacterial growth rate through its activity on DARS2 (Kasho et al., 2014).

\section{AUTHOR CONTRIBUTIONS}

All authors listed, have made substantial, direct and intellectual contribution to the work, and approved it for publication.

\section{FUNDING}

This research was part of the Center for Bacterial Stress Response and Persistence (BASP) funded by a grant from the Danish National Research Foundation (DNRF120) and by a grant from the Novo Nordisk Foundation.

Bach, T., Krekling, M. A., and Skarstad, K. (2003). Excess SeqA prolongs sequestration of ori $C$ and delays nucleoid segregation and cell division. EMBO J. 22, 315-323. doi: 10.1093/emboj/cdg020

Badrinarayanan, A., Le, T. B., and Laub, M. T. (2015). Bacterial chromosome organization and segregation. Annu. Rev. Cell Dev. Biol. 31, 171-199. doi: 10.1146/annurev-cellbio-100814-125211 
Boye, E., and Løbner-Olesen, A. (1990). The role of Dam methyltransferase in the control of DNA replication in E. coli. Cell 62, 981-989. doi: 10.1016/00928674(90)90272-G

Boye, E., Stokke, T., Kleckner, N., and Skarstad, K. (1996). Coordinating DNA replication initiation with cell growth: differential roles for DnaA and SeqA proteins. Proc. Natl. Acad. Sci. U.S.A. 93, 12206-12211. doi: 10.1073/pnas.93.22.12206

Campbell, J. L., and Kleckner, N. (1990). E. coli oriC and the dnaA gene promoter are sequestered from dam methyltransferase following the passage of the chromosomal replication fork. Cell 62, 967-979. doi: 10.1016/00928674(90)90271-F

Charbon, G., Riber, L., Cohen, M., Skovgaard, O., Fujimitsu, K., Katayama, T., et al. (2011). Suppressors of DnaA(ATP) imposed overinitiation in Escherichia coli. Mol. Microbiol. 79, 914-928. doi: 10.1111/j.1365-2958.2010.07493.x

Chodavarapu, S., Gomez, R., Vicente, M., and Kaguni, J. M. (2008). Escherichia coli Dps interacts with DnaA protein to impede initiation: a model of adaptive mutation. Mol. Microbiol. 67, 1331-1346. doi: 10.1111/j.13652958.2008.06127.x

Cui, Y., Petrushenko, Z. M., and Rybenkov, V. V. (2008). MukB acts as a macromolecular clamp in DNA condensation. Nat. Struct. Mol. Biol. 15, 411-418. doi: 10.1038/nsmb.1410

Dillon, S. C., and Dorman, C. J. (2010). Bacterial nucleoid-associated proteins, nucleoid structure and gene expression. Nat. Rev. Microbiol. 8, 185-195. doi: 10.1038/nrmicro2261

Donachie, W. D. (1968). Relationship between cell size and time of initiation of DNA replication. Nature 219, 1077-1079. doi: 10.1038/2191077a0

Donachie, W. D., and Blakely, G. W. (2003). Coupling the initiation of chromosome replication to cell size in Escherichia coli. Curr. Opin. Microbiol. 6, 146-150. doi: 10.1016/S1369-5274(03)00026-2

Filutowicz, M. (1980). Requirement of DNA gyrase for the initiation of chromosome replication in Escherichia coli K-12. Mol. Gen. Genet. 177, 301-309. doi: 10.1007/BF00267443

Flatten, I., Fossum-Raunehaug, S., Taipale, R., Martinsen, S., and Skarstad, K. (2015). The DnaA protein is not the limiting factor for initiation of replication in Escherichia coli. PLoS Genet. 11:e1005276. doi: 10.1371/journal.pgen.1005276

Flatten, I., and Skarstad, K. (2013). The Fis protein has a stimulating role in initiation of replication in Escherichia coli in vivo. PLoS ONE 8:e83562. doi: 10.1371/journal.pone.0083562

Frimodt-Moller, J., Charbon, G., Krogfelt, K. A., and Løbner-Olesen, A. (2015). Control regions for chromosome replication are conserved with respect to sequence and location among Escherichia coli strains. Front. Microbiol. 6:1011. doi: $10.3389 /$ fmicb.2015.01011

Fujimitsu, K., Senriuchi, T., and Katayama, T. (2009). Specific genomic sequences of $E$. coli promote replicational initiation by directly reactivating ADP-DnaA. Genes Dev. 23, 1221-1233. doi: 10.1101/gad.1775809

Fujimitsu, K., Su'etsugu, M., Yamaguchi, Y., Mazda, K., Fu, N., Kawakami, H., et al. (2008). Modes of overinitiation, dnaA gene expression, and inhibition of cell division in a novel cold-sensitive hda mutant of Escherichia coli. J. Bacteriol. 190, 5368-5381. doi: 10.1128/JB.00044-08

Gille, H., Egan, J. B., Roth, A., and Messer, W. (1991). The FIS protein binds and bends the origin chromosomal DNA replication, oriC, of Escherichia coli. Nucleic Acids Res. 19, 4167-4172. doi: 10.1093/nar/19.15.4167

Gon, S., Camara, J. E., Klungsøyr, H. K., Crooke, E., Skarstad, K., and Beckwith, J. (2006). A novel regulatory mechanism couples deoxyribonucleotide synthesis and DNA replication in Escherichia coli. EMBO J. 25, 1137-1147. doi: 10.1038/sj.emboj.7600990

Hansen, F. G., Christensen, B. B., and Atlung, T. (1991). The Initiator titration model: computer simulation of chromosome and minichromosome control. Res. Microbiol. 142, 161-167. doi: 10.1016/0923-2508(91)90025-6

Hardy, C. D., and Cozzarelli, N. R. (2005). A genetic selection for supercoiling mutants of Escherichia coli reveals proteins implicated in chromosome structure. Mol. Microbiol. 57, 1636-1652. doi: 10.1111/j.1365-2958.2005.04799.x

Hill, N. S., Kadoya, R., Chattoraj, D. K., and Levin, P. A. (2012). Cell size and the initiation of DNA replication in bacteria. PLoS Genet 8:e1002549. doi: 10.1371/journal.pgen.1002549
Hiraga, S., Niki, H., Ogura, T., Ichinose, C., Mori, H., Ezaki, B., et al. (1989). Chromosome partitoning in Escherichia coli: novel mutants producing Anucleate Cells. J. Bacteriol. 171, 1496-1505.

Hwang, D. S., and Kornberg, A. (1990). A novel protein binds a key origin sequence to block replication of an E. coli minichromosome. Cell 63, 325-331. doi: 10.1016/0092-8674(90)90165-B

Hwang, D. S., and Kornberg, A. (1992). Opening of the replication origin of Escherichia coli by DnaA protein with protein HU or IHF. J. Biol. Chem. 267, 23083-23086.

Johnsen, L., Flatten, I., Morigen, Dalhus, B., Bjørås, M., Waldminghaus, T., and Skarstad, K. (2011). The G157C mutation in the Escherichia coli sliding clamp specifically affects initiation of replication. Mol. Microbiol. 79, 433-446. doi: 10.1111/j.1365-2958.2010.07453.x

Kaguni, J. M. (2011). Replication initiation at the Escherichia coli chromosomal origin. Curr. Opin. Chem. Biol. 15, 606-613. doi: 10.1016/j.cbpa.2011. 07.016

Kaidow, A., Wachi, M., Nakamura, J., Magae, J., and Nagai, K. (1995). Anucleate cell production by Escherichia coli delta hns mutant lacking a histone-like protein, H-NS. J. Bacteriol. 177, 3589-3592.

Kasho, K., Fujimitsu, K., Matoba, T., Oshima, T., and Katayama, T. (2014), Timely binding of IHF and Fis to DARS2 regulates ATP-DnaA production and replication initiation. Nucleic Acids Res. 42, 13134-13149. doi: 10.1093/nar/gku1051

Kasho, K., and Katayama, T. (2013). DnaA binding locus datA promotes DnaAATP hydrolysis to enable cell cycle-coordinated replication initiation. Proc. Natl. Acad. Sci. U.S.A. 110, 936-941. doi: 10.1073/pnas.1212 070110

Katayama, T., Takata, M., and Sekimizu, K. (1996). The nucleoid protein H-NS facilitates chromosome DNA replication in Escherichia coli dnaA mutants. J. Bacteriol. 178, 5790-5792.

Kato, J., and Katayama, T. (2001). Hda, a novel DnaA-related protein, regulates the replication cycle in Escherichia coli. EMBO J. 20, 4253-4262. doi: 10.1093/emboj/20.15.4253

Kawakami, H., Keyamura, K., and Katayama, T. (2005). Formation of an ATPDnaA-specific initiation complex requires DnaA Arginine 285, a conserved motif in the AAA+ protein family. J. Biol. Chem. 280, 27420-27430. doi: $10.1074 /$ jbc.M502764200

Kim, M. S., Bae, S. H., Yun, S. H., Lee, H. J., Ji, S. C., Lee, J. H., et al. (2005). Cnu, a novel oriC-binding protein of Escherichia coli. J. Bacteriol. 187, 6998-7008. doi: 10.1128/JB.187.20.6998-7008.2005

Kitagawa, R., Mitsuki, H., Okazaki, T., and Ogawa, T. (1996). A novel DnaA protein-binding site at $94.7 \mathrm{~min}$ on the Escherichia coli chromosome. Mol. Microbiol. 19, 1137-1147. doi: 10.1046/j.1365-2958.1996.4 53983.x

Kitagawa, R., Ozaki, T., Moriya, S., and Ogawa, T. (1998). Negative control of replication initiation by a novel chromosomal locus exhibiting exceptional affinity for Escherichia coli DnaA protein. Genes Develop. 12, 3032-3043. doi: 10.1101/gad.12.19.3032

Kurokawa, K., Nishida, S., Emoto, A., Sekimizu, K., and Katayama, T. (1999). Replication cycle-coordinated change of the adenine nucleotide-bound forms of DnaA protein in Escherichia coli. EMBO J. 18, 6642-6652. doi: 10.1093/emboj/18.23.6642

Lal, A., Dhar, A., Trostel, A., Kouzine, F., Seshasayee, A. S., and Adhya, S. (2016). Genome scale patterns of supercoiling in a bacterial chromosome. Nat. Commun. 7:11055. doi: 10.1038/ncomms11055

Lee, Y. S., Han, J. S., Jeon, Y., and Hwang, D. S. (2001). The arc twocomponent signal transduction system inhibits in vitro Escherichia coli chromosomal initiation. J. Biol. Chem. 276, 9917-9923. doi: 10.1074/jbc.M00 8629200

Leonard, A. C., and Grimwade, J. E. (2011). Regulation of DnaA assembly and activity: taking directions from the genome. Annu. Rev. Microbiol. 65, 19-35. doi: 10.1146/annurev-micro-090110-102934

Leonard, A. C., and Grimwade, J. E. (2015). The orisome: structure and function. Front. Microbiol. 6:545. doi: 10.3389/fmicb.2015.00545

Leonard, A. C., and Mechali, M. (2013). DNA replication origins. Cold Spring Harb. Perspect. Biol. 5:a010116. doi: 10.1101/cshperspect.a0 10116 
Løbner-Olesen, A., Hansen, F. G., Rasmussen, K. V., Martin, B., and Kuempel, P. L. (1994). The initiation cascade for chromosome replication in wildtype and Dam methyltransferase deficient Escherichia coli cells. EMBO J. 13, $1856-1862$.

Løbner-Olesen, A., Skarstad, K., Hansen, F. G., von Meyenburg, K., and Boye, E. (1989). The DnaA protein determines the initiation mass of Escherichia coli K12. Cell 57, 881-889. doi: 10.1016/0092-8674(89)90802-7

Louarn, J., Bouche, J. P., and Louarn, J. M. (1984). Genetic inactivation of topoisomerase I suppresses a defect in initiation of chromosome replication in E. coli. Mol. Gen. Genet. 195, 170-174. doi: 10.1007/BF00332741

Lu, M., Campbell, J. L., Boye, E., and Kleckner, N. (1994). SeqA: a negative modulator of replication initiation in E. coli. Cell 77, 413-426. doi: 10.1016/0092-8674(94)90156-2

Magnan, D., and Bates, D. (2015). Regulation of DNA replication initiation by Chromosome structure. J. Bacteriol. 197, 3370-3377. doi: 10.1128/JB.0 0446-15

Margulies, C., and Kaguni, J. M. (1998). The FIS protein fails to block the binding of DnaA protein to oriC, the Escherichia coli chromosomal origin. Nucleic Acids Res. 26, 5170-5175. doi: 10.1093/nar/26.22.5170

McGarry, K. C., Ryan, V. T., Grimwade, J. E., and Leonard, A. C. (2004). Two discriminatory binding sites in the Escherichia coli replication origin are required for DNA strand opening by initiator DnaA-ATP. Proc. Natl. Acad. Sci. U.S.A. 101, 2811-2816. doi: 10.1073/pnas.0400340101

Mojica, F. J., and Higgins, C. F. (1997). In vivo supercoiling of plasmid and chromosomal DNA in an Escherichia coli hns mutant. J. Bacteriol. 179, 3528-3533.

Moolman, M. C., Krishnan, S. T., Kerssemakers, J. W., van den Berg, A., Tulinski, P., Depken, M., et al. (2014). Slow unloading leads to DNA-bound beta2-sliding clamp accumulation in live Escherichia coli cells. Nat. Commun. 5, 5820. doi: $10.1038 /$ ncomms 6820

Morigen, Boye, E., Skarstad, K., and Løbner-Olesen, A. (2001). Regulation of chromosomal replication by DnaA protein availability in Escherichia coli: effects of the datA region. Biochim. Biophys. Acta. 1521, 73-80. doi: 10.1016/S01674781(01)00292-5

Mott, M. L., and Berger, J. M. (2007). DNA replication initiation: mechanisms and regulation in bacteria. Nat. Rev. Microbiol. 5, 343-354. doi: $10.1038 /$ nrmicrol640

Nievera, C., Torgue, J. J., Grimwade, J. E., and Leonard, A. C. (2006). SeqA blocking of DnaA-oriC interactions ensures staged assembly of the E. coli pre-RC. Mol. Cell 24, 581-592. doi: 10.1016/j.molcel.2006.09.016

Nystrom, T., Larsson, C., and Gustafsson, L. (1996). Bacterial defense against aging: role of the Escherichia coli ArcA regulator in gene expression, readjusted energy flux and survival during stasis. EMBO J. 15, 3219-3228.

Ogawa, T., Yamada, Y., Kuroda, T., Kishi, T., and Moriya, S. (2002). The datA locus predominantly contributes to the initiator titration mechanism in the control of replication initiation in Escherichia coli. Mol. Microbiol. 44, 1367-1375. doi: 10.1046/j.1365-2958.2002.02969.x

Olsson, J. A., Nordstrom, K., Hjort, K., and Dasgupta, S. (2003). Eclipse-synchrony relationship in Escherichia coli strains with mutations affecting sequestration, Initiation of replication and superhelicity of the bacterial chromosome. J. Mol. Biol. 334, 919-931. doi: 10.1016/j.jmb.2003.10.029

Ozaki, S., and Katayama, T. (2012). Highly organized DnaA-oriC complexes recruit the single-stranded DNA for replication initiation. Nucleic Acids Res. 40, 1648-1665. doi: 10.1093/nar/gkr832

Ozaki, S., Noguchi, Y., Hayashi, Y., Miyazaki, E., and Katayama, T. (2012). Differentiation of the DnaA-oriC subcomplex for DNA unwinding in a replication initiation complex. J. Biol. Chem. 287, 37458-37471. doi: 10.1074/jbc.M112.372052

Petersen, C., and Møller, L. B. (2000). Invariance of the nucleoside triphosphate pools of Escherichia coli with growth rate. J. Biol. Chem. 275, 3931-3935. doi: 10.1074/jbc.275.6.3931

Polaczek, P. (1990). Bending of the origin of replication of E. coli by binding of IHF at a specific site. New Biol. 2, 265-271.

Riber, L., Fujimitsu, K., Katayama, T., and Løbner-Olesen, A. (2009). Loss of Hda activity stimulates replication initiation from I-box, but not R4 mutant origins in Escherichia coli. Mol. Microbiol. 71, 107-122. doi: 10.1111/j.13652958.2008.06516.x
Riber, L., Olsson, J. A., Jensen, R. B., Skovgaard, O., Dasgupta, S., Marinus, M. G., et al. (2006). Hda-mediated inactivation of the DnaA protein and dnaA gene autoregulation act in concert to ensure homeostatic maintenance of the Escherichia coli chromosome. Genes Dev. 20, 2121-2134. doi: 10.1101/gad.379506

Rozgaja, T. A., Grimwade, J. E., Iqbal, M., Czerwonka, C., Vora, M., and Leonard, A. C. (2011). Two oppositely oriented arrays of low-affinity recognition sites in oriC guide progressive binding of DnaA during Escherichia coli preRC assembly. Mol. Microbiol. 82, 475-488. doi: 10.1111/j.1365-2958.2011. 07827.x

Ryan, V. T., Grimwade, J. E., Camara, J. E., Crooke, E., and Leonard, A. C. (2004), Escherichia coli prereplication complex assembly is regulated by dynamic interplay among Fis, IHF and DnaA. Mol. Microbiol. 51, 1347-1359. doi: 10.1046/j.1365-2958.2003.03906.x

Ryan, V. T., Grimwade, J. E., Nievera, C. J., and Leonard, A. C. (2002). IHF and HU stimulate assembly of pre-replication complexes at Escherichia coli oriC by two different mechanisms. Mol. Microbiol. 46, 113-124. doi: 10.1046/j.13652958.2002.03129.x

Saxena, R., Fingland, N., Patil, D., Sharma, A. K., and Crooke, E. (2013). Crosstalk between DnaA protein, the initiator of Escherichia coli chromosomal replication, and acidic phospholipids present in bacterial membranes. Int. J. Mol. Sci. 14, 8517-8537. doi: 10.3390/ijms14048517

Sekimizu, K., Bramhill, D., and Kornberg, A. (1987). ATP activates dnaA protein in initiating replication of plasmids bearing the origin of the E. coli chromosome. Cell 50, 259-265. doi: 10.1016/0092-8674(87)90221-2

Simmons, L. A., Breier, A. M., Cozzarelli, N. R., and Kaguni, J. M. (2004). Hyperinitiation of DNA replication in Escherichia coli leads to replication fork collapse and inviability. Mol. Microbiol. 51, 349-358. doi: 10.1046/j.13652958.2003.03842.x

Skarstad, K., Boye, E., and Steen, H. B. (1986). Timing of initiation of chromosome replication in individual E. coli cells. EMBO J. 5, 1711-1717.

Skarstad, K., and Katayama, T. (2013). Regulating DNA replication in bacteria. Cold Spring Harb. Perspect. Biol. 5:a012922. doi: 10.1101/cshperspect.a0 12922

Skarstad, K., and Løbner-Olesen, A. (2003). Stable co-existence of separate replicons in Escherichia coli is dependent on once-per-cell-cycle initiation. EMBO J. 22, 140-150. doi: 10.1093/emboj/cdg003

Skarstad, K., Thöny, B., Hwang, D. S., and Kornberg, A. (1993). A novel binding protein of the origin of the Escherichia coli chromosome. J. Biol. Chem. 268, 5365-5370.

Skarstad, K., von Meyenburg, K., Hansen, F. G., and Boye, E. (1988). Coordination of chromosome replication initiation in Escherichia coli: effects of different dnaA alleles. J. Bacteriol. 170, 852-858.

Torheim, N. K., Boye, E., Løbner-Olesen, A., Stokke, T., and Skarstad, K. (2000). The Escherichia coli SeqA protein destabilizes mutant DnaA204 protein. Mol. Microbiol. 37, 629-638. doi: 10.1046/j.1365-2958.2000.02031.x

Usongo, V., Martel, M., Balleydier, A., and Drolet, M. (2016). Mutations reducing replication from R-loops suppress the defects of growth, chromosome segregation and DNA supercoiling in cells lacking topoisomerase I and RNase HI activity. DNA Repair 40, 1-17. doi: 10.1016/j.dnarep.2016. 02.001

Usongo, V., Tanguay, C., Nolent, F., Bessong, J. E., and Drolet, M. (2013). Interplay between type 1A topoisomerases and gyrase in chromosome segregation in Escherichia coli. J. Bacteriol. 195, 1758-1768. doi: 10.1128/JB.02001-12

von Freiesleben, U., Krekling, M. A., Hansen, F. G., and Løbner-Olesen, A. (2000a). The eclipse period of Escherichia coli. EMBO J. 19, 6240-6248. doi: $10.1093 / \mathrm{emboj} / 19.22 .6240$

von Freiesleben, U., and Rasmussen, K. V. (1991). DNA replication in Escherichia coli $\operatorname{gyrB}(\mathrm{Ts})$ mutants analysed by flow cytometry. Res. Microbiol. 142, 223-227. doi: 10.1016/0923-2508(91)90034-8

von Freiesleben, U., and Rasmussen, K. V. (1992). The level of supercoiling affects the regulation of DNA replication in Escherichia coli. Res. Microbiol. 143, 655-663. doi: 10.1016/0923-2508(92)90060-2

von Freiesleben, U., Rasmussen, K. V., Atlung, T., and Hansen, F. G. (2000b). Rifampicin resistant initiation of chromosome replication from oriC in ihf mutants. Mol. Microbiol. 37, 1-8. doi: 10.1046/j.1365-2958.2000. 02060.x 
von Freiesleben, U., Rasmussen, K. V., and Schaechter, M. (1994). SeqA limits DnaA activity in replication from oriC in Escherichia coli. Mol. Microbiol. 14, 763-772. doi: 10.1111/j.1365-2958.1994.tb0 1313.x

Wang, X., Montero, L. P., and Rudner, D. Z. (2013). Organization and segregation of bacterial chromosomes. Nat. Rev. Genet. 14, 191-203. doi: 10.1038/ nrg3375

Weigel, C., Messer, W., Preiss, S., Welzeck, M., Boye, M., and Boye, E. (2001). The sequence requirements for a functional Escherichia coli replication origin are different for the chromosome and a minichromosome. Mol. Microbiol. 40, 498-507. doi: 10.1046/j.1365-2958.2001.02409.x

Weitao, T., Nordstrom, K., and Dasgupta, S. (1999). Mutual suppression of mukB and seqA phenotypes might arise from their opposing influences on the Escherichia coli nucleoid structure. Mol. Microbiol. 34, 157-168. doi: 10.1046/j.1365-2958.1999.01589.x

Weitao, T., Nordström, K., and Dasgupta, S. (2000). Escherichia coli cell cycle control genes affect chromosome superhelicity. EMBO Rep. 1, 494-499. doi: 10.1093/embo-reports/kvd106

Wold, S., Crooke, E., and Skarstad, K. (1996). The Escherichia coli Fis protein prevents initiation of DNA replication from oriC in vitro. Nucleic Acids Res. 24, 3527-3532. doi: 10.1093/nar/24.18.3527

Wu, H. Y., Shyy, S. H., Wang, J. C., and Liu, L. F. (1988). Transcription generates positively and negatively supercoiled domains in the template. Cell 53, 433-440. doi: 10.1016/0092-8674(88)90163-8
Yamanaka, K., Zheng, W., Crooke, E., Wang, Y. H., and Inouye, M. (2001). CspD, a novel DNA replication inhibitor induced during the stationary phase in Escherichia coli. Mol. Microbiol. 39, 1572-1584. doi: 10.1046/j.13652958.2001.02345.x

Yun, S. H., Ji, S. C., Jeon, H. J., Wang, X., Kim, S. W., Bak, G., et al. (2012). The CnuK9E H-NS complex antagonizes DNA binding of DicA and leads to temperature-dependent filamentous growth in E. coli. PLoS ONE 7:e45236. doi: 10.1371/journal.pone.0045236

Conflict of Interest Statement: The authors declare that the research was conducted in the absence of any commercial or financial relationships that could be construed as a potential conflict of interest.

The reviewer MM declared a past co-authorship with the author ALO to the handling Editor, who ensured that the process met the standards of a fair and objective review.

Copyright (C) 2016 Riber, Frimodt-Møller, Charbon and Løbner-Olesen. This is an open-access article distributed under the terms of the Creative Commons Attribution License (CC BY). The use, distribution or reproduction in other forums is permitted, provided the original author(s) or licensor are credited and that the original publication in this journal is cited, in accordance with accepted academic practice. No use, distribution or reproduction is permitted which does not comply with these terms. 